\title{
Bilgi ve İletişim Teknolojileri Kullanımı, İstihdam ve Ekonomik Büyüme İlişkisi ${ }^{1}$
}

\author{
Nurcan Ece ${ }^{2}$ \\ Güldenur Çetin ${ }^{3}$
}

Başvuru:14 Ocak 2022

Kabul:4 Şubat 2022

\section{Özet}

Bu çalışmada BİT kullanımı, istihdam ve ekonomik büyüme ilişkisi açıklanmaya çalışılmıştır. $\mathrm{Bu}$ doğrultuda 35 OECD ülkesine ait 2010-2019 yılları arasındaki veriler panel veri analizi yöntemi ile incelenmiştir. Çalışmada ekonomik büyüme değişkeni olarak, kişi başına düşen GSYİH oranı, istihdam değişkeni olarak, istidamın nüfusa oranı ve BİT değişkenleri olarak bireysel internet kullanıcıları, sabit geniş bant abonelikleri ve aktif mobil geniş bant abonelikleri baz alınmıştır. Çalışma sonucunda BİT kullanımını ifade eden bireysel internet kullanıcıları, sabit geniş bant abonelikleri değişkenleri istihdam ve ekonomik büyüme üzerine herhangi bir etki yaratmazken, aktif mobil geniş bant abonelikleri değişkeni istihdam ve ekonomik büyüme üzerinde pozitif etki gösterdiği tespit edilmiştir.

Anahtar Kelimeler: Bilgi ve İletişim Teknolojisi, İstihdam, Ekonomik Büyüme, Panel Veri Analizi

JEL Kodları: O39, E24, O40, C33

\footnotetext{
${ }^{1}$ Bu makale, Sorumlu Yazar'ın İstanbul Ticaret Üniversitesi, Sosyal Bilimler Enstitüsü, İktisat Anabilim dalında "Bilgi ve İletişim Teknolojileri Kullanımı, İstihdam ve Ekonomik Büyüme İlişkisi" adlı yüksek lisans tezinden türetilmiştir.

${ }^{2}$ Sorumlu Yazar, İstanbul Ticaret Üniversitesi, Sosyal Bilimler Enstitüsü, İktisat Anabilim Dalı Yüksek Lisans Öğrencisi, nrcn.gltkn09@hotmail.com, ORCID ID: 0000-0002-0991-0284

${ }^{3}$ Dr. Öğretim Üyesi, İstanbul Ticaret Üniversitesi, İşletme Fakültesi, gadiguzel@ticaret.edu.tr ORCID ID: 00000003-3341-7016
}

InTraders International Trade Academic Journal Vol.4 Iss.2 e-ISSN-2667-4408

www.intraders.org 
The Use of Information and Communication Technologies, The Relationship between Employment and Economic Growth

\begin{abstract}
In this study, the use of ICT has been tried to explain the relationship between employment and economic growth. Accordingly, data of 35 OECD countries between 2010-2019 were examined by panel analysis method. In the study, as variable of economic growth, the ratio of GDP per capita and as a variable of employment, the ratio of employment to the population $(+15)$. As ICT variables, individual internet users, fixed broadband subscriptions and active mobile broadband subscriptions were taken as the basis. As a result of the study, Of the variables expressing the use of ICT, individual internet users and fixed broadband subscriptions do not have any impact on employment and economic growth, but Active mobile broadband subscriptions have been found to have a positive impact on employment and economic growth.

Keywords: Information and Communication Technology, Employment, Economic Growth, Panel Data Analysis
\end{abstract}

JEL Codes: O39, E24, O40, C33 


\section{Giriș}

Geçmişten günümüze dünya ülkelerinde sosyo-ekonomik gelişimler, teknolojik ilerlemeler ile paralel seyretmektedir. Teknolojik ilerlemelerin küresel hale gelmesi bilgi ve iletişim teknolojileri kullanımları ile kolaylaşmakta ve dolaylı olarak ekonomik yapının, bilgi ekonomisi geçiş-gelişim sürecine katkı sağlamaktadır. Bilginin üretilmesi, toplanması, işlenmesi, depolanması, iletilmesi ve kullanılmasını sağlayan bir sistem bütünü olan BİT'in bu süreci desteklediği görülmektedir (Özkan \& Çelik, 2018; Artan, Hayaloğlu, \& Baltac1, 2014).

Bilgi ve iletişim teknolojilerinin yaygınlaşması, üretim sürecine dahil edilmesi verimliliği arttıran bir etkendir bu daha kısa sürede ve daha az maliyetle daha fazla çıtı üretilmesinden kaynaklanmaktadır. Ve dolaylı olarak ekonomik büyümeye pozitif yönde katkı sağlayan bir etken olarak görülmesi ile sonuçlanmaktadır.

Aynı zamanda BİT kullanımının yaygınlaşması ve üretim sürecine dahil edilmesi yeni sektörler, pazarlar ve meslekler oluşturduğundan istihdamı arttırıcı bir etki gösterdiğini söyleyebilirken, ürünlerin piyasada sürekli yenilenmesi eski üretim tipine ait sektörlere, pazarlara ve mesleklere olan ilgiyi ve talebi azalttığından üreticilerin stratejilerini değiştirmelerine sebep olurken, sürece ayak uyduramayan üreticiler özelinde ise istihdamı daraltıcı bir etki gösterdiğini söyleyebiliriz (Appiah-Otoo \& Song, 2021; Yangınlar \& Köksal, 2022).

Bu çalışmada 35 OECD ülkesinde BİT kullanımının, istihdam ve ekonomik büyüme üzerine etkileri tahmin edilmeye çalışılmıştır. Bu kapsamda çalışmada ilk olarak BİT kullanımının istihdam ve ekonomik büyüme üzerine etkileri ele alınıp, literatür taraması ile desteklenmiştir. Literatür incelendiğinde genel olarak teknolojik gelişme göstergelerinin ekonomik büyümeye etkisi olumlu yöndeyken bazı göstergelerin etkisiz ya da olumsuz etkilediği görülmüştür ve BİT kullanımının istihdama olan etkisi konusunda literatürde herhangi bir fikir birliğine varılmadığ sonucuna ulaşılmaktadır.

Çalışmanın devamında araştırma metodu ve veri seti açıklanmış, çalışma sonucu elde edilen ekonometrik analiz bulguları değerlendirilmiştir ve son olarak literatür ve ekonometrik analiz bulguları 1şı̆̆ında çalışma sonuç kısmı ile sonlandırılmıştır. 


\section{BİT, Ekonomik Büyüme ve İstihdam Üzerine Literatür Taraması}

Literatürde yapılan ampirik çalışmalar doğrultusunda teknolojik gelişme göstergesi olarak ele alınan değişkenlerin ekonomik büyümeye pozitif katkı sunduğu söylenebilmekteyken, teknolojik gelişmelerin istihdama olan etkisi konusunda fikir birliğine varılmamıştır.

Appiah-Otoo ve Song (2021), 45 gelişmiş, 58 gelişmekte olan ve 20 az gelişmiş ülkeler olmak üzere toplamda 123 ülke üzerinden 2002-2017 yılları arasında Panel analiz yöntemi ile BİT'in ekonomik büyüme üzerine etkileri gelişmiş, gelişmekte olan ve az gelişmiş ükeler ele alınarak karşılaştırmalı olarak analiz yapılmıştır. Yapılan çalışma sonucunda her ülke grubunda mobil, internet, sabit geniş bant oranlarının ekonomik büyümeye pozitif etki sağladığı görülmüştür.

Koç (2021), Türkiye verileri üzerinden 2001-2018 yılları arasında lineer kesikli-zaman stokastik durum-uzay modelleri kullanılmış olup büyümeyi açıklamak için 9 adet bağımısız değişken (bireysel internet kullanımı, kamu harcamaları, kişi başına düşen cep telefonu abonelikleri, dış ticaret haddi, bilişim teknolojileri dış ticaret haddinin toplam dış ticaret haddine oranı, yatırımlar, net dış varlıklar, özel sektöre bankalar tarafından verilen krediler) baz alınarak model kurulmuştur. Yapılan çalışma sonucunda bireysel internet kullanımı ve cep telefonu aboneliğinin büyümeyi arttırıcı etkisi olduğu görülmektedir.

Tunalı ve Güz (2021), 79 ülkenin verileri üzerinden 2010-2016 yılları arasında Panel analiz yöntemiyle BİT gelişim endeksininin ekonomik büyüme üzerine etkisi incelenmek üzere çalışma yapılmış ve sonuç olarak BİT gelişim endeksinin ekonomik büyümeye pozitif anlamda etkisi olduğu gözlemlenmiştir.

Yeşiltaş ve Artar (2021), çalışmalarında teknolojik gelişmelerin, işgücü ve istihdam üzerine etkileri konusu geniş bir literatür taraması ile desteklemiştir. Çalışma sonucunda literatürde fikir birliğinin olmadığını ve araştırmacıların konuya iyimser veya karamsar yaklaştıklarını belirtilmiştir. Çalışmaya göre iyimser yaklaşan araştırmacıların görüşü, teknolojik gelişmelerin uzun vadede yeni iş alanları yaratarak istihdamı arttıracağı yönündeyken karamsar yaklaşan araştırmacıların görüşü, teknolojik gelişmeler sonucunda üretimde işgücü talebi azalacağından, istihdamda daralma meydana gelecektir. Sonuç olarak iş gücünün nitelik kazanması gerektiği ve işgücüne yapılan yatırımlarının artması gerektiği belirtilmiştir.

Topçu (2021), Türkiye verileri üzerinden 1996-2017 yılları arasında AMG yöntemi kullanılmış olup teknolojik gelişimin istihdam üzerine etkisi sektörel bazda analiz edilmiştir. 
Çalışmalarından edinilen sonuçlara göre teknolojik gelişme, tarım sektörü istihdamı üzerine etkisi negatifken, sanayi ve hizmet sektörü istihdamı üzerine etkisi pozitiftir.

Myovella, Karacuka ve Haucap (2020), 41 SSA (Sahra Altı Afrika) ülkesi ve 33 OECD ülkesi olmak üzere toplamda 74 ülke üzerinden 2006-2016 yılları arasında GMM (Genişletilmiş Momentler Metodu), OLS (En Küçük Kareler Yöntemi) modellerini kullanarak dijitalleşmenin ekonomik büyümeye etkisini ele alınan ülkeler bazında karşılaştırmalı olarak analiz yapılmıştır. Çalışmalarından edindikleri sonuçlara göre ekonomik büyümeye mobil teknolojilerin etkisi SSA ülkelerinde fazla iken OECD ülkeleri için bu etki önemli değildir. Bireysel internet kullanım oranı her ülke grubu için ekonomik büyümeye pozitif etki sağlamaktadır ve bununla beraber SSA ülkelerinde internet alt yapılarındaki az gelişmişlik nedeniyle ekonomik büyümeye etkisi düşüktür.

Hekim Yılmaz ve Kırışkan (2020), Türkiye verileri üzerinden 1980-2015 yılları arasında birim kök testleri ve eş bütünleşme testleri ile telekomünikasyon alt yapısının ekonomik büyüme üzerine etkileri analiz edilmiştir ve sonuç olarak telekomünikasyon alt yapısının gelişmesi, ekonomik büyümeyi arttırıcı etkiye sahiptir.

Farhadi ve Fooladi (2020), 142 ülkenin verileri üzerinden 2006-2015 yılları arasında GMM (Genişletilmiş Momentler Metodu) modellerini kullanarak BİT erişiminin ekonomik büyüme üzerine etkisi analiz edilmiştir. Çalışmalarından edindikleri sonuçlara göre ekonomik büyümeye BİT'in etkisi yüksek gelirli ülkelerde daha fazla olmasına karşın her ülkede arttırıcı etkiye sahip olmaktadır.

Alper (2018), 24 ülke üzerinden 1996-2016 yılları arasında Panel veri yöntemi kullanılarak iki model oluşturulmuş ve BİT'in, ekonomik büyüme ve işsizlik ilişkisini analiz etmiştir. Çalışmadan edindikleri sonuçlara göre BİT, ekonomik büyümeyi arttırır ve işsizliği azaltır.

Niebel (2018), 59 ülke üzerinden 1995-2010 yılları arasında regresyon analizi yapılarak BİT ve ekonomik büyüme ilişkisini ülke gruplarına göre (gelişmiş ülke, gelişmekte olan ülke ve gelişmemiş ülke) açıklanmaya çalışılmıştır. Çalışma sonuçlarına göre BİT, ekonomik büyümeye katkıda bulunmaktadır. (Niebel, 2018)

Algan, Özmen ve Karlılar (2017), 2000-2014 yılları arasında G-20 ülkeleri (7 Gelişmiş ve 13 Gelişmekte Olan) üzerinden BİT ve ekonomik büyüme ilişkisi panel veri yöntemi ile analiz edilmiştir. Çalışmadan edinilen sonuçlara göre gelişmiş ülkelerde pozitif bir etki söz 
konusuyken, gelişmekte olan ülkelerde ve G-20 ülkelerinin tamamında negatif bir etki söz konusudur.

Piva ve Vivarelli (2017), 11 Avrupa ülkesi verileri üzerinden 1998-2011 yılları arasında Sistem Genelleştirilmiş Momentler yöntemi kullanılarak istihdam ve teknolojik değişme ilişkisi ele alınmıştır. Çalışmada elde edilen bulgular sonucunda, teknolojik gelişme parametresi olarak ele alınan AR-GE harcamalarının orta ve yüksek teknoloji sektörlerine etki ettiği görülürken, düşük teknolojili sektörlere etki etmediği görülmüştür.

Mike ve Laleh (2016), G-20 ülkelerinin (7 Gelişmiş ve 13 Gelişmekte Olan) verileri üzerinden 1991-2012 yılları arasında Panel veri yöntemi kullanılarak analiz yapılmıştır. Çalışmalarından edindikleri sonuçlara göre BİT ve istihdam ilişkisi gelişmiş ülkelerde, 1991-1999 yılları arasında pozitif ve anlamlı iken 2000-2012 yılları arasında negatif ve anlamlıdır. Gelişmekte olan ülkelerde ise, 1991-1999 yılları arasında etkisizken, 2000-2012 yılları arasında pozitif ve anlamlı bir ilişki vardır.

Türedi (2013), 23 Gelişmiş, 30 Gelişmekte olan ülkeler olmak üzere 53 ülke üzerinden 1995 2008 yılları arasında Sabit ve Tesadüfi Etkiler Panel veri yöntemi ile analiz yapmıştır ve çalışma sonucunda BİT’nin ekonomik büyüme üzerinde gelişmiş ülkelerde, gelişmekte olan ülkelere göre daha yüksek olmasına karşın tüm ülkelerde arttırıcı etkiye sahip olmasıdır.

Ahmed ve Ridzuan (2013), 8 ülkeye (Çin, Endonezya, Japonya, Singapur, Kore, Filipinler, Malezya, Tayland) ait veriler üzerinden 1975-2006 yılları arasında Panel Tahmini yaklaşımı ile analiz yapmışlardır. Çalışma sonucunda BİT'in ekonomi büyüme üzerinde etkisinin olumlu olduğu sonucuna ulaşılmıştır.

Matei ve Savulescu (2012), AB üye ülkelerinin verileri üzerinden 2006-2010 yılları arasında ampirik analiz yapılmıştır. Çalışma sonucunda BİT'in GSYİH'a olan katkısı rekabet gücünü de arttıracaktır.

Farhadi, Ismail ve Fooladi (2012), 159 ülkenin verileri üzerinden 2000-2009 yılları arasında GMM (Genişletilmiş Momentler Metodu) modellerini kullanarak analiz yapmışlardır. Çalışmalarından edindikleri sonuçlara göre ekonomik büyümeye BİT'in yükssek gelirli ülkelerde daha fazla olmasına karşın her ülkede arttırıcı etkiye sahip olmasıdır. 


\section{Ekonometrik Yöntem, Veri Seti ve Kaynağı}

2010-2019 yılları arasında 35 OECD ülkesine ait BİT kullanımını ifade eden göstergeler, istihdam ve ekonomik büyüme arasındaki ilişki panel veri analizi yöntemiyle 2 Model kurularak çözümlenmeye çalışılmıştır. Yapılacak analizde 1. Modelde BİT kullanım göstergeleri, ekonomik büyüme ilişkisini, 2. Modelde BİT kullanım göstergeleri, istihdam ilişkisi kapsamında uygulanacak ekonometrik modeller aşağıdaki denklemlerde verilmiştir.

$\log \left(G S Y I H_{i t}\right)=\alpha_{i t}+\beta_{1 i, t} \log \left(B I_{i t}\right)+\beta_{2 i, t} \log \left(S G B_{i t}\right)+\beta_{3 i, t} \log \left(M G B_{i t}\right)+\varepsilon_{i t}$

$\log \left(I S T_{i t}\right)=\alpha_{i t}+\beta_{1 i, t} \log \left(B I_{i t}\right)+\beta_{2 i, t} \log \left(S G B_{i t}\right)+\beta_{3 i, t} \log \left(M G B_{i t}\right)+\varepsilon_{i t}$

Denklemde yer alan i panel verinin birim boyutunu, t zaman boyutunu ifade eder. $\beta_{\mathrm{i}}(\mathrm{i}=1,2,3$, bağımsız değişkenlerin (BI, MGB, SGB) bağımlı değişkenler (IST ve GSYIH) üzerindeki etkilerinin tahminini ifade eden tahmin parametrelerini, $\alpha$ sabit terimi, $\varepsilon$ ise denklem hata terimlerini ifade etmektedir.

Çalışmada ele alınan her iki model için bağımlı değişkenler ekonomik büyüme ve istihdam iken bağımsız değişken olarak kullanılan BİT kullanımı üç parametre ile açıklanmıştır. Kullanılan veriler, kaynakları ve çalışmada ele alınan ülkeler Tablo 1,2'de verilmiştir.

Tablo 1. Model 1ve 2'ye Ait Veri Seti - Kaynağ1

\begin{tabular}{lll}
\hline \hline Değişken & Açıklama & Kaynak \\
\hline \hline GSYİH & Kişi başına GSYİH (ABD doları) & World Bank \\
IST & İstihdamın nüfusa oranı, (15+, toplam (\%)) & World Bank \\
BI & Bireysel internet kullanıcıları (\%) & ITU \\
SGB & Sabit geniş bant abonelikleri (100 kişi başına) & ITU \\
MGB & Aktif mobil geniş bant abonelikleri (100 kişi başına) & ITU \\
\hline \hline
\end{tabular}

Tablo 3. Çalışmada Ele Alınan Ülkeler

\begin{tabular}{ccccc}
\hline \hline Almanya & Finlandiya & Kosta Rika & Polonya & İrlanda \\
ABD & Fransa & Letonya & Portekiz & İspanya \\
Avusturya & Güney Kore & Litvanya & Slovak Cumhuriyeti & İsrail \\
Belçika & Hollanda & Lüksemburg & Slovenya & İsveç \\
Birleşik Krallı & Japonya & Macaristan & Türkiye & İsviçre \\
Danimarka & Kanada & Meksika & Yunanistan & İtalya \\
Estonya & Kolombiya & Norveç & Çek Cumhuriyeti & İzlanda \\
\hline \hline
\end{tabular}

InTraders International Trade Academic Journal Vol.4 Iss.2 e-ISSN-2667-4408

www.intraders.org 


\section{Bulguların Değerlendirilmesi}

Bu çalışmada, 35 adet OECD ülkesi için 2010 ile 2019 yıllarını kapsayan veri seti oluşturulmuştur. Panel veri modelinde birim etkisinin olması bu etkinin sabit etki veya tesadüfi etki olma durumuna göre farklılık göstermektedir. Tahmin yönteminde farkl1lıkların anlaşılabilmesi için önce birim etkisinin olup olmadığını incelemek gerekmektedir, eğer ki birim etkisi varsa sonrasında sabit ve rastsal etki modellerinin tanımlanması yapılmalıdır (Tatoğlu, 2012).

Birim etkisinin incelenmesi maksadıyla yapılan Breusch-Pagan (1980) Lagrange test ististiği sonucunda her iki model içinde birim etkilerinin görüldüğü söylenebilmektedir. Breusch-Pagan (1980) Lagrange test istatistiği sonucu Tablo 4’te verilmiştir.

Tablo 4. Breusch-Pagan (1980) Lagrange Birim Etkisi Testi

\begin{tabular}{|c|c|c|c|c|c|}
\hline & \multicolumn{2}{|c|}{ Model 1} & \multicolumn{3}{|c|}{ Model 2} \\
\hline & $\sigma_{\mathrm{u}}^{2}$ & $\sigma_{u}$ & & $\sigma_{\mathrm{u}}^{2}$ & $\sigma_{u}$ \\
\hline Log(GSYIH) & 0.4726513 & 0.6874964 & Log(IST) & 0.0136249 & 0.1167258 \\
\hline$\varepsilon$ & 0.00979 & 0.0989442 & $\mathbf{E}$ & 0.0008198 & 0.0286327 \\
\hline$\mu$ & 0.1423325 & 0.3772698 & $\mu$ & 0.0087396 & 0.0934857 \\
\hline $\mathrm{X}^{2(01}$ & $71 * * *$ & Sig. $=0.000$ & \multicolumn{2}{|c|}{$\mathrm{X}^{2(01)}=1026.37^{* * *}$} & Sig. $=0.000$ \\
\hline
\end{tabular}

Not: ***(\%1) anlamlılık düzeyinde $\mathrm{H}_{0}$ hipotezi reddedilmiştir, $\mathrm{x}^{2}$ : Ki-Kare test istatistiğini, $\sigma_{\mathrm{u}}^{2}$ :

Birim Etki Varyansın1, $\sqrt{\sigma_{u}^{2}}=\sigma_{u}$ : Standart Hatay1, $\varepsilon$ : Hata Terimini ve $\mu$ : Birim Etkisini ifade eder.

Her iki modelde hesaplanan test istatistiği anlamlılık değerleri incelendiğinde modeller için \% 1 anlamlılık düzeyinde birim etkisinin sıfır olduğu yönündeki sıfır hipotezlerinin reddedildiği görülmektedir. $\left(\mathrm{x}^{2(01)}=952.71\right.$ ve $\mathrm{x}^{2(01)}=1026.37 \mathrm{Sig}$. $\left.<0.01\right)$.

Bunun üzerine modellerdeki birim etkilerinin modellere tutarlı bir şekilde yansıtabilmek üzere kullanılması gereken panel tahmin yöntemini seçmek için Hausman (1978) testi istatistiği uygulanmıştır. Hausman testi birim etkilerinin sabit mi yoksa tesadüfi etki olup olmadığını test etmektedir. Hausman test istatistiği sonucunda sabit etkiler tahmincilerinin geçerli olduğu görülmektedir. Hausman test istatistiği sonuçları Tablo 5'te verilmiştir. 
Tablo 5. Hausman Test İstatistiği

\begin{tabular}{lcccrrc}
\hline \hline \multirow{2}{*}{ Değişken } & \multicolumn{3}{c}{ Model 1 } & \multicolumn{3}{c}{ Model 2 } \\
\cline { 2 - 7 } & SE(b) & TE(B) & Fark (b-B) & SE(b) & TE(B) & Fark (b-B) \\
\hline \hline $\log (\mathbf{B I})$ & -0.05881 & -0.01067 & -0.04814 & -0.07115 & -0.08817 & 0.01702 \\
$\log (\mathbf{S G B})$ & 0.08628 & -0.17672 & 0.26300 & 0.05062 & 0.05733 & -0.00671 \\
$\log (\mathbf{M G B})$ & 0.04548 & 0.08916 & -0.04368 & 0.03979 & 0.04095 & -0.00116 \\
\hline \hline Test & $\mathrm{X}^{2(03)}=189.23^{* * *}$ & Sig $=0.001$ & $\mathrm{X}^{2(03)}=14.24^{* * *}$ & \multirow{2}{*}{ Sig $=0.003$} \\
\hline \hline
\end{tabular}

Not: $* * *(\% 1)$ anlamlılık düzeyini, $\mathrm{X}^{2}$ : Ki-Kare test istatistiğini, *Parantez içi serbestlik derecesini gösterir, b: Sabit Etkileri B: Tesadüfi Etkileri , (b-B) etkiler arası farkı ifade eder.

Modeller için hesaplanan katsayılara ve katsayılar arasındaki farklara bakıldığında söz konusu farkların yüksek olduğu görülürken, test istatistiği anlamlılık değerleri incelendiğinde $\% 1$ anlamlılık düzeyi için her iki model için de tesadüfi etkiler tahmincisinin data tutarlı bir tahminci olduğu yönündeki sıfir hipotezinin reddedildiği, sabit etkiler tahmincilerinin daha tutarlı olduğu yönündeki alternatif hipotezlerin ise kabul edildiği görülmektedir. $\left(\mathrm{x}^{2(01)}=189.23\right.$ ve $\mathrm{x}^{2(01)}=14.24$, Sig. $\left.<0.01\right)$

Breusch-Pagan (1980) Lagrange testi ile tespit edilen birim etkilerinin, Hausman (1978) testi bulguları doğrultusunda sabit etkiler modelinin tutarlılı̆g konusundaki karalar sonucu modelin sabit etkiler modeli tahmini ve temel varsayım sınamaları ile açıklanmaya çalışılmış ve Tablo 6 'da verilmiştir. 
Tablo 6. Model Tahminleri

\begin{tabular}{|c|c|c|c|c|c|c|c|c|}
\hline \multirow{2}{*}{ Değişken } & \multicolumn{4}{|c|}{ "Model 1} & \multicolumn{4}{|c|}{ Model 2} \\
\hline & $\beta$ & S.H ${ }^{\text {Cluster }}$ & $\mathbf{Z}$ & Sig. & $\beta$ & S.H H $^{\text {Cluster }}$ & $\mathbf{z}$ & Sig. \\
\hline$\overline{\log (B I)}$ & -0.0107 & 0.2258 & -0.05 & 0.963 & -0.0882 & 0.0532 & -1.66 & 0.107 \\
\hline $\log ($ SGB $)$ & -0.1767 & 0.1630 & -1.08 & 0.286 & 0.0573 & 0.0488 & 1.17 & 0.248 \\
\hline $\log (M G B)$ & 0.0892 & 0.0403 & $2.21 * *$ & 0.034 & 0.0410 & $0.0150 * *$ & 2.74 & 0.010 \\
\hline Sabit & 10.5912 & 0.8697 & $12.18 * * *$ & 0.000 & 4.0330 & $0.1784 * * *$ & 22.61 & 0.000 \\
\hline
\end{tabular}

\begin{tabular}{|c|c|c|c|c|}
\hline \multicolumn{5}{|c|}{ Tanısal İstatistikler } \\
\hline \multirow{2}{*}{ F Test } & \multicolumn{2}{|c|}{$\mathrm{F}(3,34)=3.23 * *$} & \multicolumn{2}{|c|}{$\mathrm{F}(3,34)=6.79 * * *$} \\
\hline & \multicolumn{2}{|c|}{ Sig. $=0.034$} & \multicolumn{2}{|c|}{ Sig. $=0.001$} \\
\hline \multirow{2}{*}{ Pesaran Test } & \multicolumn{2}{|c|}{$\square^{2}(10)=26.153 * * *$} & \multicolumn{2}{|c|}{$\square^{2}(10)=10.193 * * *$} \\
\hline & \multicolumn{2}{|c|}{ Sig. $=0.000$} & \multicolumn{2}{|c|}{ Sig. $=0.000$} \\
\hline LBI & \multicolumn{2}{|c|}{0.87024} & \multicolumn{2}{|c|}{0.79393} \\
\hline D.W. & \multicolumn{2}{|c|}{0.59125} & \multicolumn{2}{|c|}{0.38446} \\
\hline \multirow{2}{*}{$\begin{array}{l}\text { Modifiye } \\
\text { Test }\end{array}$} & \multicolumn{2}{|c|}{$\square^{2}(35)=402.020 * * *$} & \multicolumn{2}{|c|}{$\square^{2}(35)=15298.320 * * *$} \\
\hline & \multicolumn{2}{|c|}{ Sig. $=0.000$} & \multicolumn{2}{|c|}{ Sig. $=0.000$} \\
\hline \multirow{3}{*}{ Determinasyon } & Grupsuz & $\mathrm{R}^{2}=0.0725$ & Grupsuz & $\mathrm{R}^{2}=0.3192$ \\
\hline & Gruplar Arası & $\mathrm{R}^{2}=0.3398$ & Gruplar Arası & $\mathrm{R}^{2}=0.0120$ \\
\hline & Tüm & $\mathrm{R}^{2}=0.2545$ & Tüm & $\mathrm{R}^{2}=0.0345$ \\
\hline
\end{tabular}

Not: $* * *(\% 1), * *(\% 5), *(\% 10)$ anlamlllık düzeylerini, F: F Test istatistiğini, $\square^{2}$ : Ki-Kare test istatistiğini, *Parantez içi serbestlik derecesini, Cluster: Arellano, Froot ve Rogers kümelenmiş standart hataları ifade etmektedir.

Model 1 ve 2 için Tablo 6 incelendiğinde, Pesaran testi bulguları sonucunda modellerde yer alan birimler ve hata terimleri arasındaki ilişki \%1 anlamlılık düzeyinde istatistiksel olarak önemlidir, farklı bir ifade ile modelde yatay kesit bağımlılı̆̆ görülmektedir. (Model 1: $\mathrm{x}^{2(10)}=$ 26.153, Sig. <0.01), (Model 2: $\mathrm{x}^{2(10)}=10.193 .153$, Sig.<0.01).

LBI ve D.W testi bulguları incelendiğinde her iki modelde değerin 2'den küçük olduğu görülmektedir ve iki modelde otokorelasyon varlığı söz konusudur. Modelde sabit varyans varsayımını sınayan Modifiye edilmiş Wald testi istatistikleri incelendiğinde ise $\% 1$ anlamlılık düzeyinde istatistiksel olarak önemli bir değişen varyans sorunu olduğu dikkat çekmektedir. (Model 1: $\mathrm{x}^{2(35)}=402.020$, Sig. $\left.<0.01\right),\left(\right.$ Model 2: $\mathrm{x}^{2(35)}=15298.320$, Sig. $\left.<0.01\right)$ 
Modellerde görülen yatay kesit bağımlılı̆̆ı sebebiyle kullanılan Cluster (kümelenmiş) Arellano, Froot ve Rogers kümelenmiş standart hataların yatay kesit ile birlikte otokorelasyon ve /veya değişen varyans sorunlarına karşı da dirençli olduğu bilindiğinden Cluster standart hatalar ile yapılan tahminin etkin olduğu varsayılmaktadır.

Model 1 parametrelerinin toplu anlamlılık test olan F testi istatistiklerine göre tahmin edilen model, \%5 anlamlılık düzeyinde istatistiksel olarak anlamlı bir modeldir. $(F(3,34)=3.23$, Sig.<0.05),

Model 2 parametrelerinin toplu anlamlılık test olan F testi istatistiklerine göre tahmin edilen model, \%1 anlamlılık düzeyinde istatistiksel olarak anlamlı bir modeldir. $(F(3,34)=6.79$, Sig. $<0.01)$

Bireysel internet kullanıcıları $\log (\mathrm{BI})$ değişkeninin, ekonomik büyüme ve istihdam üzerine önemli bir etkisinin olmadığı görülmektedir. (Model 1: $\beta=-0.0107$, Sig.>0.10), (Model 2: $\beta=$ -0.0107$, Sig. $>0.10)$

Sabit geniş bant abonelikleri $\log (\mathrm{SGB})$ değişkeninin, ekonomik büyüme ve istihdam üzerine önemli bir etkisinin olmadığ1 görülmektedir. (Model 1: $\beta=-0.1767$, Sig.>0.10), (Model 2: $\beta=0.0532$, Sig. $>0.10)$

Aktif mobil geniş bant abonelikleri Log(MGB) değişkenin ise ekonomik büyüme ve istihdam üzerine önemli ve pozitif bir etkisinin olduğu görülmektedir. (Model 1: $\beta=-0.1767$, Sig.<0.05), (Model 2: $\beta=0.1784$, Sig. $<0.05$ )

\section{Sonuç}

35 OECD ülkesine ait 2010 ile 2019 yılları arasında ele alınan BİT kullanım değişkenleri ile istihdam, ekonomik büyüme ilişkisi çalışma kapsamında incelenmiştir. Ekonomik büyüme kişi başına düşen GSYİH (ABD doları cinsinden) ile, istihdam oranı (İstihdamın nüfusa oranı, (15+, toplam \%)) ile ve BİT kullanımı literatürle paralel olarak, bireysel internet kullanıcıları (\%), sabit geniş bant abonelikleri (100 kişi başına) ve aktif mobil geniş bant abonelikleri (100 kişi başına) parametreleri ile iki ekonometrik model kurularak açıklanmıştır ve panel analiz yöntemi ile analiz edilmiştir.

Analiz sonuçlarına göre 2 Modelde de bağımlı değişkenler ve bağımsız değişkenler arasında anlamlı bir ilişki vardır. Ve BİT kullanım parametrelerinden bireysel internet kullanıcıları (\%) ve 100 kişi başına sabit geniş bant abonelikleri değişkenleri istihdam ve ekonomik büyüme 
üzerinde istatistiksel olarak önemli bir etki yaratmazken, 100 kişi başına aktif mobil geniş bant abonelikleri değişkeni istihdam ve ekonomik büyüme üzerinde pozitif bir etki yaratmaktadır. 100 kişi başına sabit geniş bant aboneliklerinin analiz sonuçlarına göre istihdam ve ekonomik büyüme ile ilişkisinin etkisiz çıkmasının sebebi özellikle son yıllarda 100 kişi başına aktif mobil geniş bantların, 100 kişi başına sabit geniş bantlara göre daha fazla talep edilmesi ve yatırım almasından kaynaklı olduğu düşünülmektedir.

Çalışmada elde edilen bulgular literatür ile parallel olmakla beraber ve BİT kullanımının, istihdam ve ekonomik büyüme ilişkisi anlamlı sonuçlanmıştır.

Sonuç olarak, literatürden de elde edilen edinimlere göre, günümüzde sosyal ve ekonomik yapının gelişmesi için temel faktörlerden birinin bilgi olduğu görülmektedir. Bilginin işlenmesini sağlan BİT araçları ise bu gelişime destek sağlamaktadır. BİT kullanımının arttırılması ve teşvik edilmesi, BİT erişimi altyapılarının güçlendirilmesi, BİT yatırımlarının ve BİT üretiminin arttırılması ekonomik göstergeleri iyileştirmekte ve ülkelerin bu yönde gelişimleri küresel rekabet ortamında varlıklarını devam ettirebilmeleri için önem arz etmektedir. 


\section{Kaynakça}

Algan, N., Özmen, M., \& Karlılar , S. (2017). Bilgi ve İletişim Teknolojilerinin Ekonomik Büyüme Üzerine Etkisi: G-20 Ülkeleri İ̧̧in Bir Analiz. Çukurova Üniversitesi IiBF Dergisi, 21(1), 1-24.

Alper, F. Ö. (2018). Bilgi ve Illetişim Teknolojilerinin Ekonomik Büyüme ve İşsizlik Üzerine Etkisi: Seçilmiş AB Ülkeleri ve Türkiye Örneği. Yasama Dergisi(36), 45-65.

Appiah-Otoo, I., \& Song, N. (2021). The impact of ICT on economic growth-Comparing rich and poor countries. Telecommunications Policy, 45(2).

Artan, S., Hayaloğlu, P., \& Baltacı, N. (2014). Bilgi ve İletişim Teknolojilerindeki Gelişmelerin İktisadi Büyüme Üzerindeki Etkisi: Geçiş Ekonomileri Örneği. Atatürk Üniversitesi iktisadi ve Idari Bilimler Dergisi, 28(1), 199-214.

Artar, O., \& Yeşiltaş, C. (2021). Ekonomideki Dijital Dönüşüm ve İstihdam Üzerindeki Etkisi. Working Paper Series, 2(1), 43-52.

Farhadi, M., \& Fooladi, M. (2020). Impact of Information and Communication Technology Access on Economic Growth. Journal of Practical Information Technology, 1(3), 11-22.

Farhadi, M., Fooladi, M., \& Ismail, R. (2012). Information and Communication Technology Use and Economic Growth. PLOS ONE, 7(11), 1-7.

Hekim Yılmaz, D., \& Kırışkan, I. (2020). Türkiye'de Telekomünikasyon Altyapısı ve Ekonomik Büyüme. Türk Dünyası Sosyal Bilimler Dergisi(92), 55-84.

Koç, Ü. (2021). Bilişim Teknolojileri ve Ekonomik Büyüme. Üçüncü Sektör Sosyal Ekonomi Dergisi, 56(2), 12311244.

Matei, A., \& Savulescu, C. (2012). Empirical analysis of ICT, economic growth and competitiveness in the EU. Proceedings of the International Conference on ICT Management (ICTM 2012), (s. 42-58). Wroclaw.

Mike , F., \& Laleh, M. M. (2016). Bilgi ve İletişim Teknolojilerinin İstihdam Üzerine Etkisi: Seçili Ülkeler Üzerine Bir Uygulama. Atatürk Üniversitesi Sosyal Bilimler Enstitüsü Dergisi, 20(2), 601-614.

Myovella, G., Karacuka, M., \& Haucap, J. (2020). Digitalization and economic growth: A comparative analysis of Sub-Saharan Africa and OECD economies. Telecommunications Policy, 44(2).

Niebel, T. (2018). ICT and economic growth - Comparing developing, emerging and developed countries. World Development(104), 197-211.

Özkan, G., \& Çelik, H. (2018). Bilgi İletişim Teknolojileri ile Ekonomik Büyüme Arasındaki illişki: Türkiye İçin Bir Uygulama. Uluslararası Ticaret ve Ekonomi Araştırmaları Dergisi, 2(1), 1-15.

InTraders International Trade Academic Journal Vol.4 Iss.2 e-ISSN-2667-4408

www.intraders.org 
Piva, M., \& Vivarelli, M. (2017). Technological Change and Employment: Were Ricardo and Marx Right? IZA Institute of Labor Economics, 4-34.

Ridzuan, R., \& Ahmed, E. M. (2013). The Impact of ICT on East Asian Economic Growth: Panel Estimation Approach. Journal of the Knowledge Economy, 4(4), 540-555.

Tatoğlu, F. Y. (2012). Panel Veri Ekonometrisi. İstanbul : Beta Yayıncılık.

Topçu, E. (2021). Teknolojik Gelişmenin İstihdam Üzerindeki Etkisi: Türkiye Ekonomisi Üzerine Sektörel Bir Analiz. Nevşehir Hacı Bektaş Veli Üniversitesi SBE Dergisi, 11(2), 481-491.

Tunalı, H., \& Güz, T. (2021). Bilgi ve İletişim Teknolojileri Gelişim Endeksi ve Ekonomik Büyüme iliş̧kisinin Panel Veri Modelleri ile Karşılaştırmalı Analizi. iktisadi Idari ve Siyasal Araştırmalar Dergisi, 6(15), 249-261.

Türedi, S. (2013). Bilgi Ve İletişim Teknolojilerinin Ekonomik Büyümeye Etkisi: Gelişmiş Ve Gelişmekte Olan Ülkeler İçin Panel Veri Analizi. Gümüşhane Üniversitesi Sosyal Bilimler Elektronik Dergisi(7), 298-323.

Yangınlar, G., \& Köksal, C. (2022). Radyo Frekansı Tanımlama (RFID) Teknolojisinin Tedarik Zinciri Performansına Etkileri: Lojistik Endüstrisinde Bir Vaka Çalışması. Journal of Productivity(Özel Sayı), 91108.

InTraders International Trade Academic Journal Vol.4 Iss.2 e-ISSN-2667-4408

www.intraders.org 